\title{
The attitudes and experiences of registered nurses who teach and mentor nursing students in the acute care setting
}

\author{
Linda Evans ${ }^{1,2}$, Margaret Costello², Hallie Greenberg ${ }^{2}$, Patrice K. Nicholas ${ }^{1,2}$ \\ 1. MGH Institute of Health Professions, Boston MA, United States. 2. Brigham and Women's Hospital, Boston, MA, United \\ States.
}

Correspondence: Linda Evans. Address: MGH Institute of Health Professions, $361^{\text {st }}$ Avenue, Charlestown, MA. Telephone: 021-294-557. Email: levans3@partners.org.

Received: May 31, 2012

Accepted: July 25, $2012 \quad$ Published: February 1, 2013

DOI : $10.5430 /$ jnep.v3n2p67

URL: http://dx.doi.org/10.5430/jnep.v3n2p67

\begin{abstract}
Background: The pedagogy of clinical learning for nursing students in acute care settings has transitioned from an apprentice model to one necessitating more dynamic interactions between clinical staff nurses and learners. Clinical nurses must provide theoretical knowledge, share clinical expertise, and model professional behavior to nursing students in an increasingly complex medical system. Our clinical learning environments encompass significant technological advances, shortened length of patient stay, and institutional climates which are often dominated by financial constraints, all which have the potential to impact the teaching and learning environment, and consequently, patient outcomes. Therefore, the purpose of this study was to examine the attitudes and experiences of registered nurses in acute care settings who clinically teach and mentor nursing students in order to understand pedagogical strengths, weaknesses, and opportunities.
\end{abstract}

Methods: A qualitative study was undertaken to explore the attitudes and experiences of registered nurses who participate in the clinical teaching and mentoring of nursing students in an acute care setting. Semi- structured interviews were carried out using a focus group format. Three models of clinical education were represented within the sample. The first model consisted of a faculty member affiliated with an institution of higher learning overseeing the clinical experiences of six to eight students on one clinical unit for approximately 14 weeks. The second model was the preceptor-based model wherein an experienced nurse is paired with a student for approximately 240 hours during a ten-week period. The third model was the "Dedicated Education Unit" (DEU). The DEU leverages unit-based clinical staff nurses in a dual role as a clinical faculty member affiliated with a university-based nursing program and utilized a one-to-one or one-to-two teacher to learner ratio.

Results: Thematic content analysis was carried out between and within the focus groups. The findings suggest that: unit-specific philosophical pedagogies highly impact the overall experiences of teacher and learner; commonly shared, clearly articulated goals are imperative; and a firmly established and refined partnership between the student's academic institution and the health care facility may be critical to the successful outcome of the experience. Moreover, the participants articulated a perceived link between teaching students and enhanced communication on the unit, utilization of evidenced-based practice, and improved patient outcomes.

Conclusion: The results presented here are based on focus group interviews with three groups of participants who are involved in the clinical education of nursing students. The six themes that emerged serve as a framework for understanding 
the comprehensive, time-intensive, patient-focused, and role-developmental approaches in which clinical nurses engage to support excellent clinical learning experiences for student nurses.

\section{Key words}

Clinical nursing education, Nursing study, Preceptor, Dedicated education unit, Qualitative research, Education models

\section{Background and significance}

There are a variety of approaches to clinical nursing education. Broadly speaking however, the pedagogy of clinical learning for nursing students in acute care settings has transitioned from an apprentice model to one necessitating more dynamic interactions between clinical staff nurses and learners. In this study, three distinct models were represented. The first model consisted of a faculty member affiliated with an institution of higher learning overseeing the clinical experiences of six to eight students on one clinical unit for approximately 14 weeks. The second model was the preceptor-based model wherein an experienced nurse is paired with a student for approximately 240 hours during a ten-week period. The third model was the "Dedicated Education Unit" (DEU) ${ }^{[1]}$. The DEU leverages unit-based clinical staff nurses in a dual role as a clinical faculty member affiliated with a university-based nursing program and utilizes a one-to-one or one-to-two teacher to learner ratio.

Clinical nurses must provide theoretical knowledge, share clinical expertise, and model professional behavior to nursing students in an increasingly complex medical system. Our clinical learning environments encompass significant technological advances, shortened length of patient stay, and institutional climates which are often dominated by financial constraints, all which have the potential to impact the teaching and learning environment, and consequently, patient outcomes. Therefore, the purpose of this study was to examine the attitudes and experiences of registered nurses in acute care settings who clinically teach and mentor nursing students in order to understand pedagogical strengths, weaknesses, and opportunities.

\section{Literature review}

Authors of the extant literature support the use of staff nurses as clinical experts ${ }^{[2,3]}$. In the role of a preceptor, the staff nurse provides the student nurse with education via sharing of clinical expertise. As clinical experts, staff nurses have a significant impact on student learning by role modeling and imparting clinical knowledge ${ }^{[4]}$. Although these authors described the importance of supporting staff nurses in their role as a preceptor of nursing students, there are few researchers who have quantified specific factors that are involved in educating student nurses or who have documented the qualitative experiences of the teaching-learning endeavor.

Yonge, Myrick, Ferguson and Lughana ${ }^{[5]}$ interviewed eight nurses from various inpatient units including medical surgical and critical care areas. The overriding theme from the analysis was "safe passage" for both the patient and the student. Safe passage was accomplished through the process of teaching and a concise explanation of the role of the preceptor. Their findings suggested that preceptors have an essential role in the education of nursing students. The authors concluded that healthcare institutions must ensure that nurses who are also responsible for teaching students are given the necessary support, recognition, and resources.

In a hermeneutic phenomenological study, Ohrling and Hallberg ${ }^{[6-9]}$ explored the meaning of the staff nurses' experience serving as a clinical teacher ("preceptor") of a student nurse ("preceptee"), the meaning of the experience of this learning model for the student, as well as defining the preceptor-preceptee relationship. The researchers conducted 17 individual student and staff nurse interviews in two Swedish hospitals. Two main themes emerged from this study: the preceptor shelters the student when learning, and serves as the facilitator for the students' learning. Eight subthemes related to understanding of the meaning of a preceptorship included: gaining insight into students experiences; knowledge 
acquisition; identifying goals for practice; identifying learning needs; providing learning opportunities and illustrations; conferring with others about their mentees' learning; assessing competence; conversing; and reflecting. The authors concluded that a need exists for additional preceptor support and development of the role of the preceptor.

Rush, Peel, and McCracken ${ }^{[10]}$ examined nursing students' perceptions of a summer extern program. Using focus groups, the investigators sought to determine the students' experiences of the time spent with the 13 preceptors over a 6-week period. Students described their learning experiences a in a variety of ways leading investigators to extract themes encompassing the entire patient care experience. Themes included: learning time management, prioritization of care, patient interaction skills, expansion of critical thinking skills, and acquisition of a variety of technical skills. The authors found that preceptors played a major role in acculturating students to the fast-paced, specialized technical health care environment. The researchers' results indicated that the students viewed the nurses as empowering teachers and had the ability to create an environment conducive to learning.

Wieland, Altmiller, Door, and Wolf ${ }^{[11]}$ examined the perspectives of students, liaison faculty, and clinical preceptors to describe the clinical experience for BSN students during their precepted senior practicum. These authors found that with preceptor guidance, students developed skills in the following areas: increased awareness of patients' needs, taking initiative, organization, and prioritizing patient care. Students also began to assimilate to being included as part of a team ${ }^{[11]}$. Preceptors serve as coaches and role models to student nurses. The preceptor role also helps ease the students' transition into the nursing profession by helping to both socialize and model professional behaviors. Preceptors support student nurses in the development of critical thinking and decision-making skills. The preceptor role also serves to provide students with important feedback throughout the preceptor process ${ }^{[12]}$.

The profession of nursing continues to strive to optimize the teaching and learning environment for its next generation. Studies have qualitatively explored the issue, concluding that the clinical teaching of nursing students greatly impacts the staff nurse's roles and responsibilities, and the student's learning. The current study explored the topic with focus groups within one institution, but representative of three distinct pedagogical environments to determine if, and where, similarity and differences in attitudes and experiences exist.

\section{Methods}

An application was submitted to the Institutional Review Board (IRB) to obtain ethical clearance to conduct the study. The IRB provided a statement of exempt review. A convenience sample of participants was recruited electronically using data provided by the institution's Orientation Coordinator. Each potential participant received a letter of explanation about the study's purpose and was asked to respond to that communication if interested in participating in a focus group.

This qualitative study utilized semi-structured interviews with three focus groups of nursing staff members ( $\mathrm{N}=13)$ who were engaged in the process of clinical education. One focus group consisted of six clinical nurses who had had either a one-to-one relationship with a Baccalaureate student in their last semester of their educational program, or had worked collaboratively with a clinical faculty member on their unit with baccalaureate nursing students. The second group consisted of five advanced practice nurses who had mentored nurse practitioner students in a one-on-one preceptor-based model. The third group consisted of two clinical nurses who were staff members on the DEU, and who served as clinical teachers of third year students at a partnering university in a one-to-one or two-to-one teacher-learner ratio.

The letter of explanation regarding the study which was used during recruitment was again made available for review and verbal consent was obtained from each participant. Demographic data were also collected. The interviews were conducted at a time and place convenient to the participants and were 90-120 minutes in length. An interview guide was used to focus the questions and to provide a series of prompting questions to encourage dialogue. The interview guide was an iterative document, as is the expectation in qualitative research. The questions were amended to clarify and verify emerging 
themes. Each focus group was audio recorded to allow for verbatim transcription by a research assistant. Extensive field notes were taken during the focus groups and peer debriefing among the researchers occurred after each session. These activities, in addition to member checks which were utilized during the data analysis procedure, assured the trustworthiness of the study's procedures.

\section{Data analysis}

Demographic data for the participants $(\mathrm{N}=13)$ were analyzed. Variables collected included: clinical role, years working as a nurse, years working at the institution, educational preparation, years teaching and precepting students, and time committed to teaching. Additionally, the participants estimated the time spent in preparation for the student including gathering evidenced-based resources and counseling and advising the student (see Table 1).

Table 1. Demographic Variables

\begin{tabular}{ll}
\hline Item & Description \\
\hline Clinical Role & Staff Nurse $\mathrm{n}=8$; Advanced Practice Nurse $\mathrm{n}=5$ \\
Years in Nursing Practice & $\mathrm{M}=19.5$; SD 11.16 \\
Years Working at Study Setting & $\mathrm{M}=12.2$; SD 9.9 \\
Highest Level of Educational Preparation & Diploma in Nursing $\mathrm{n}=1$ \\
& Bachelor's Degree $\mathrm{n}=7$ \\
& Master's Degree $\mathrm{n}=4$ \\
Years Teaching Students & Doctoral Degree $\mathrm{n}=1$ \\
Days per Year Teaching Students & $\mathrm{M}=9.1$ yrs; SD 6.6 yrs \\
Additional Hours per Shift Preparing, Counseling, Advising & $\mathrm{M}=36$ days; SD 25 days \\
\hline
\end{tabular}

Prior to commencing thematic coding of the transcripts, the audio tapes were listened to a second time and compared with the transcribed version for accuracy. Thematic content analysis was then carried out and emerging themes identified. After coding all transcripts, the analysis turned to within group and between group comparisons.

\section{Findings}

Six themes emerged from the date (see Table 2).

Table 2. Themes
1. There is an extensive time commitment related to teaching nursing students
2. There is variability to the experience depending on specific pedagogy
3. The role of the school of nursing instructor and the link with the academic institution is critical
4. Teaching students likely affects patient outcomes
5. Professional Role development is key
6. The DEU enhances student flourishing

\subsection{Extensive time commitment related to teaching}

All participants discussed the intensive time commitment related to teaching nursing students and each clarified that this was balanced by the rewards. The time commitment was reported as the "entire shift" in the preceptor-based and Dedicated Education Unit models, and up to three and a half hours when students were accompanied by faculty. Additionally, each group reported time spent preparing and evaluating the students, which was generally in addition to the actual clinical teaching time with the student. 
One nurse commented:

"[Educating nursing students] was something I thought about doing but it's hard enough to do your job on the floor sometimes without doing teaching too and you get no special treatment for doing it. If you are orienting a new nurse or a newly-licensed nurse (NLN) to your pod they can lighten your assignment or whatever. It doesn't happen with nursing students."

"People [other staff] understand that I am teaching and fully responsible for the patients and clinical teaching. Understanding the role of the student and the nurse [is important]. Normally, I can see a patient in ten minutes, but now I have to take a half an hour [to do the same work with a student]."

Another nurse noted:

"You are teaching and role-modeling, which is part of teaching [during the entire shift]. So even if you are not talking to the student you are basically saying I am about to do [this] . . watch how I do that. So we have an 8-hour shift, [then] it is all 8 hours [of teaching]."

Further the time-intensive element was described by one advanced practice nurse:

“... I usually have two sessions, a morning and an afternoon [clinic] session and you know, they run from 8:30 to 12:30 and then from 1 to $4 \mathrm{pm}$. So in that time you know you're teaching, going over the patient with the student and then going in and doing the exam so they are observing you so it's really ... there's never any down time [in teaching]. "

Another nurse stated:

"And in fact, probably, you know depending on what you're going to be dealing with that week-or learning with the student, you may be spending time, I know I do-outside my clinical time where I am at home and I am trying to prepare things for the student, particularly the area that I work in, which is very specialty-focused."

\subsection{Variability of the experience of teaching nursing students}

Participants indicated that the experience was very different depending on the type of student, group and the clinical specialty of the unit. The philosophy of the unit and commitment to teaching were essential elements for participants and several identified that their units were committed to educating the next generation of nurses. Other participants reported that the experience varied depending on the abilities of the students with some students requiring more time by the clinical nurse for preparation to care for patients. Many staff reported receiving a more difficult assignment when assigned with a student as they were viewed as “an extra pair of hands". This was often seen as detrimental to the student's learning experience.

\subsection{The role of the school of nursing instructor and the link with the academic institution is critical}

Several participants identified the important role of the school of nursing faculty/instructor and the link with the academic institution as critical to the outcomes of the experience. The clinical nurses and advanced practice nurses noted that frequent communication with the instructor assigned to the students is essential to the success of any of the teaching/learning models.

One respondent commented on the critical role of the faculty/instructor: 
"Our teaching is often guided by the clinical instructors because they'll tell you what they need, where they need it [for the students] . . . when I have a really good instructor, we'll pick out a [complex] patient or a [less complex] patient specific to the student's needs."

\subsection{Teaching students likely affects patient outcomes}

Perhaps the most important findings of this study revealed that the participants believed that optimal patient outcomes are linked to teaching/learning situations. Many staff identified the important work of teaching as providing additional time to communicate with patients and families, address discharge planning, and to carefully focus on physical, psychological, social, and spiritual needs of patients and families. Changes in patients' status were also identified as optimized because of the presence of a student in the teaching-learning process. The belief that outcomes were enhanced by student presence was strongly identified in all three focus groups.

As one nurse noted:

"I think it [teaching nursing students] actually makes the patient outcome better. You know, sometimes when you do that internal thinking process you might miss a step but when you're talking to a student and you're explaining for instance that this patient has had breast pain for five years and she has negative imaging...what are we going to do for her? So you have to talk it through step-by-step, where if it's internalized in me.....it might become rote in some ways. I think it does take...more time and more energy to teach; it's tiring at the end of the day after you've had a student. But I think too when you have a student you are so much more cautious of your interactions and how you act with your patients...not that we are not always trying to think about that. But I can only think that it enhances the outcome."

Another nurse on the DEU unit stated: "I think the patients get more attention ... they get more TLC because they have two people that are talking to them. With the students the patients are more inquisitive ... and [the patients] start to ask the students questions." A second nurse on the DEU unit offered the following comments about enhanced patient outcomes: "I had one patient today ... my student went in to [perform the assessment and obtain] vital signs and said the patient's oxygen level was only 87\%. The patient said to the student ... no, you have to leave it on longer ... and so I think the patients get into [the educational process with nursing students].”

\subsection{Professional role development is key}

The role transition of nursing students to professional nurse was another theme that was identified as an integral component in the teaching/learning environment. Many clinical nurses described the importance of serving as a preceptor in order to model professional behavior and prepare the student for the seamless integration into becoming a newly-licensed nurse. One participant said:

"I sort of feel that there's a professional responsibility that we all share [in] our profession and it's to the next generation [of nurses] in our contract with society. I believe that. Beyond that, I feel we chose to practice in an academic medical center and so by virtue of that fact, we should be on board with training [nursing] students...I also feel that the mission statement of the hospital puts it right out there the commitment to training the next generation of medical providers and that includes students."

\subsection{The DEU model enhances student flourishing}

The Dedicated Education Unit (DEU) represents one model which actively involves nursing staff to serve as the clinical instructor for students. This model includes a clinical faculty appointment by the student's academic institution for the participating unit's staff member, and when serving in the faculty role, they are not also counted as unit staff. This assures that there are increased resources specifically responsible for student learning. 
In this study, the students assigned to the DEU were engaged in their first acute care learning experience and the facility's goal was to plan to invite these students to complete subsequent clinical experiences on their unit, including their clinical immersion experience immediately prior to graduation. If the students were successful, and staffing patterns allowed, the students would be considered for employment following graduation. Optimally, the students would require a shortened orientation period and experience a hastened role transition, as they would be fully oriented to the unit environment, staff members, and philosophy. The goal of preparing students for unit-specific employment is not typical in other units or with other teaching-learning models at the study site.

All of the focus group participants (including those who were not staff members on the DEU) believed that the DEU model enhanced students' clinical judgment and reasoning skills through repetitive experiences and consistent supervision. Additionally, it was noted that the DEU presented an overall culture of commitment by the entire staff on the unit, rather than by only those who were precepting students. Many participants noted that the uniqueness of this model lies in that there are more staff members on the unit when students are present and this.

\section{Discussion}

The participants' experiences in this study suggest that the role and responsibilities of clinical teaching by staff nurses are complex. There exists some variability in the experience however, depending on the learning environment.

The DEU model, as described by Moscato and colleagues ${ }^{[1]}$ and in the present study offered innovation in clinical teaching, engagement by professional staff in seamless roles as faculty for schools of nursing, and focused on student-centered learning needs. The DEU model enhanced students' clinical judgment and reasoning skills through repetitive experiences and consistent supervision and the staff and students had common goals of forging a long-term relationship.

Similar to the results of Ohrling and Hallberg's ${ }^{[6-9]}$ studies, the present study uncovered the meaning of staff nurses' and advanced practice nurses' experiences in the rigorous role of preceptor. Relationships that were developed among expert nurses and those entering the profession were described in the interviews and developed as themes. Staff and advanced practice nurses identified the importance of supporting the learning experiences of students while developing the relationships with patients, supporting excellent outcomes for patients and students, and forging a strong relationship with the school of nursing and faculty. The data from this study also supported the earlier findings of Rush, Peel and McCracken ${ }^{[10]}$ who found that nurses gained a sense of empowerment in their nursing roles through their ability to create an environment conducive to learning for nursing students.

\section{Conclusion}

The results presented here are based on focus group interviews with three groups of participants who are involved in the clinical education of nursing students.

The six themes that emerged serve as a framework for understanding the comprehensive, time-intensive, patient-focused, and role-developmental approaches in which clinical nurses engage to support excellent clinical learning experiences for student nurses. In the education of nursing students, clinical nursing staff and students encounter milestones in role development. The participants in this study described the complex role enactment of teacher in approaching the varied experiences of students; the role of the school of nursing instructor; and advancing a student's role development. Clinical nurses identified the extensive time commitment related to teaching which involved one-to-one mentoring during the shift, as well as preparatory work and comprehensive evaluation of students. For those clinical nurses who worked more closely with school of nursing faculty, the teaching role involved fewer hours ( 3.5 hours per shift) while the preceptor-based model was described by one participant as "teaching across all hours of the shift while engaged with students." 
Addressing patient outcomes, participants describe enhanced patient outcomes in the domains of communication; assessment, intervention, and evaluation of patient status; patient teaching; establishing relationships with patients and families; patient safety, teaching about documentation, policies and procedures; and earlier discussion of discharge planning. Although time-intensive, the required elements of teaching by clinical nurse uncovered a contextual approach to patients and families that believed enhanced patient outcomes.

Finally, educational roles-whether student nurse or clinical nurse-require substantial critical thinking and clinical judgment that was evident in the descriptions of all participants in the focus groups. Advanced clinical knowledge, excellent assessment skills, and a comprehensive approach to patient-and family-focused care were described in the context of the teaching process. Each participant explored the concept of teaching nursing students as a partnership with knowledge acquisition, role development, professional socialization, and growth occurring for the clinical nurse and the nursing student.

The strength of this study was the focus-group methodology approach that engaged thirteen clinical nurses in discussion about their comprehensive work in the clinical education of nursing students. The analyses of the data extend the current knowledge base on the education of nursing students in acute care settings. The time-intensive, analytical work of clinical nurses in teaching critical-thinking skills is essential for advancing the nursing practice of student nurses.

Future study of the teaching/learning environments in nursing should include dyads of clinical nurses and nursing students; registered nurses seeking Master of Science in nursing degrees and doctoral students (both Doctor of Nursing Practice and Doctor of Philosophy students) in preceptor-based relationships in clinical practice and research settings. Focus groups of nursing students who are educated in the acute care setting would also advance the knowledge of the unique experience of students in the acute care setting as a learning environment.

\section{References}

[1] Moscato SR., Miller J., Logsdon K., Weinberg S., Chorpenning L. Dedicated education unit: an innovative clinical partner education model. Nursing Outlook. 2007; 55(1): 31-37. PMid:17289465 http://dx.doi.org/10.1016/j.outlook.2006.11.001

[2] Kowalski K., Horner M., Carroll K., Center D., Foss K., Jarrett S., Kane A. Nursing Clinical Faculty Revisited: The Benefits of Developing Staff Nurses as Clinical Scholars. Journal for Continuing Education in Nursing. 2007; 38(2): 69-75. PMid:17402378

[3] Landers MG. The Theory-Practice Gap in Nursing: The Role of the Nurse Teacher. Journal of Advanced Nursing. 2000; 33(6): 1550-1556. PMid:11136425 http://dx.doi.org/10.1046/j.1365-2648.2000.01605.x

[4] Donner CL., Levonian C., Slutsky P. Move to the Head of the Class: Developing Staff Nurses as Teachers. Journal for Staff Development. 2005; 21: 277-283. http://dx.doi.org/10.1097/00124645-200511000-00007

[5] Yonge O., Myrick F., Ferguson L., Lughana F. Promoting effective preceptorship experiences. Journal of Ostomy, Wound, and Continence Nursing. 2005; 32 (6): 325-327.

[6] Ohrling K., Hallberg IR. The Meaning of Preceptorship: Nurses’ Lived Experience of Being a Preceptor. Journal of Advanced Nursing. 2001; 33(4): 530-540. PMid:11251741 http://dx.doi.org/10.1046/j.1365-2648.2001.01681.x

[7] Ohrling K., Hallberg IR. Nurses’ Lived Experience of Being a Preceptor. Journal of Professional Nursing. 2000 ; 16 (4): $228-239$. PMid:10932997 http://dx.doi.org/10.1053/jpnu.2000.7825

[8] Ohrling K., Hallberg IR. Student Nurses’ Lived Experience of Preceptorship. Part 1: In Relation to Learning. International Journal of Nursing Studies. 2000; 37 (1): 13-23. http://dx.doi.org/10.1016/S0020-7489(99)00054-1

[9] Ohrling K., Hallberg IR. Student Nurses’ Lived Experience of Preceptorship. Part 2: In Relation to Learning, International Journal of Nursing Studies. 2000; 37(1): 25-36. http://dx.doi.org/10.1016/S0020-7489(99)00055-3

[10] Rush KL., Peel K., McCracken B. Empowered Learning on the Inside: An Externship Experience. Nursing Education Perspectives. 2004; 25(6): 284-291. PMid:15675376

[11] Wieland D., Altmiller G., Dorr M., Wolf K. Clinical Transitions of Baccalaureate Nursing Students During Preceptored, Pregraduation Practicums. Nursing Education Perspectives. 2007; 28 (6): 315-321. PMid:18240737

[12] Swihart D. The Effective Nurse Preceptor Handbook ( $2^{\text {nd }}$ ed.). Marblehead, MA: HCPro Inc. 2007. 